\title{
La fortificación de Teruel durante el siglo XIX: un paisaje efímero
}

\section{The fortification of Teruel during the nineteenth century: a fleeting landscape}

\author{
Miguel Sancho Mir ${ }^{1}$, Luis Agustín Hernández² \\ Universidad de Zaragoza \\ Beatriz Martín Domínguez ${ }^{3}$ \\ Escuela Universitaria Politécnica de la Almunia
}

\begin{abstract}
RESUMEN
El marcado carácter militar de la fundación cristiana de Teruel se materializó en el aspecto inexpugnable del asentamiento, ubicado en lo alto de una muela y provisto de un complejo sistema defensivo. Sin embargo, la formación y transformación de este sistema no fue un hecho exclusivo de la Edad Media, sino que se trata de un proceso continuo que duró hasta el mismo siglo XIX. El presente artículo pretende recuperar el paisaje urbano fortificado de este último periodo, ya que, como consecuencia del convulso siglo XIX, la ciudad se transformó, adaptándose para su defensa, con un complejo sistema, que en su mayor parte no sobreviviría a su propia centuria, y del que quedan contados vestigios. El análisis de estos, así como de diversos documentos, entre los que se encuentran grabados, algunas de las primeras fotografías de la ciudad o cartografías históricas, han permitido recomponer una imagen que parece haber caído en el olvido.
\end{abstract}

Palabras clave: cartografía; patrimonio desaparecido; paisaje urbano; guerras carlistas; muralla.

\begin{abstract}
The strong military character of the Christian foundation of Teruel was materialized in the impregnable aspect of the settlement, located at the top of a plateau and with a complex defensive system. However, the development of the defensive system didn't take place exclusively during the Middle Ages; rather, it was an ongoing process that even continued until the nineteenth century. This research seeks to recover the fortified urban landscape of this last period. A period that, due to a tumultuous nineteenth century, saw the city transform and adapt for its own defence with a complex system, that hardly survived its own century and of which there are just a few vestiges nowadays. The analysis of these, as well as of several documents, such as some of the first photos of the city, engravings or historical mapping, has made it possible to rebuild a forgotten image.
\end{abstract}

Key words: mapping; missing heritage; cityscape; Carlist wars; wall.

Recibido: 31-01-2017. Aceptado: 19-06-2017. Publicado online: 12-12-2017

\section{Cómo citar este artículo / Citation}

Sancho Mir, M., Agustín Hernández, L. y Martín Domínguez, B. 2017: "La fortificación de Teruel durante el siglo XIX: un paisaje efímero", Arqueología de la Arquitectura, 14: e056. doi: http://dx.doi.org/10.3989/arq.arqt.2017.011

\section{Copyright}

(C) 2017 CSIC. Este es un artículo de acceso abierto distribuido bajo los términos de una licencia de uso y distribución Creative Commons Attribution (CC-by) España 3.0.

\footnotetext{
${ }^{1}$ misanmi@unizar.es / ORCID iD: http://orcid.org/0000-0003-2903-475X.

${ }^{2}$ lagustin@unizar.es / ORCID iD: http://orcid.org/0000-0002-0397-9766.

${ }^{3}$ beamardo@unizar.es / ORCID iD: http://orcid.org/0000-0001-7974-8270.
} 


\section{INTRODUCCIÓN HISTÓRICA}

En los albores del siglo XIX, en 1807, se produjo la consentida ocupación francesa de España para la invasión de Portugal, sin embargo, las intenciones ocultas del ejército galo iban más allá: el derrocamiento de la casa de Borbón para implantar su propia dinastía. Frente a la delicada situación, se produjo, el dos de mayo de 1808, el levantamiento de la población, lo que dio origen a la guerra de la Independencia, un preludio de lo que sería el siglo XIX: un periodo convulso en el que la inestabilidad fue producida por el ambiente bélico en el que se desarrolló.

Tras la caída de Zaragoza, como consecuencia del segundo Sitio de la ciudad en febrero de 1809, en mayo se estableció en Teruel una Junta Superior de Aragón y parte de Castilla (Lafoz 2009). Las tropas francesas, al mando del mariscal Suchet, llegaron a Teruel, que fue ocupado, sin apenas resistencia, el 20 de diciembre de 1809 (Villanueva 2010a: 129; Madoz 1849: XIV, 747), situación que se alargó hasta que en 1813 se produjo la salida del ejército galo de la ciudad. Durante la presencia francesa se decretaron varias ordenaciones del territorio - como la de departamentos de 1809 o la de prefecturas de 1810 (Madoz 1849: XIV, 708) - que, finalmente, resultaron en la división política promulgada en junio de 1812 (Villanueva 2010a: 129) que convirtió a Teruel en capital de una de las cuatro provincias en las que se dividió Aragón: Zaragoza, Huesca, Alcañiz y Teruel.

Con la expulsión de los franceses en 1813, entró en vigor la Constitución de Cádiz - aprobada el 19 de marzo de 1812- en todo el territorio español. Situación política efímera pues, con la vuelta de Fernando VII, quien había prometido acatar las disposiciones de las Cortes, se restauró el absolutismo tras la derogación de la Carta Magna el 4 de mayo de 1814 en la ciudad de Valencia. La delicada situación del país provocó la revolución de 1820, dando paso al llamado Trienio Liberal (18201823), periodo en el que se volvió a aplicar la Constitución de 1812, y en el que la ciudad de Teruel recuperó su importancia política-administrativa al ser designada como capital de provincia por la ley aprobada en enero de 1822 (Madoz 1849: XIV, 709), aunque apenas tendría vigencia. Al igual que en el periodo de la ocupación francesa, el territorio se ordenó en cuatro provincias, sin embargo, cambió la configuración del mismo pues ahora eran Zaragoza, Huesca, Calatayud y Teruel.

La condición de Teruel como centro rector de un amplio territorio no se produjo de forma estable y ya definitiva hasta la reforma promovida por Javier de Burgos y plasmada en el Real Decreto aprobado el 30 de noviembre 1833 (Madoz 1849: XIV, 709), cuando se estableció la actual división provincial.

La recién estrenada capitalidad designó un papel protagonista a Teruel en la primera guerra carlista (1833-1840), como centro rector del Estado a nivel político y militar en una zona especialmente sensible al conflicto frente al territorio carlista del Maestrazgo. En diciembre de 1835 (Rújula 2014: 326) las tropas carlistas, que transitaban las cercanías de Teruel, intentaron un ataque sobre la ciudad, pero sin éxito. El aumento en la intensidad bélica durante los próximos años provocó una situación crítica para la población, que vio como, durante demasiado tiempo, se interrumpiría su rutina social y económica. Otro ataque a Teruel se produjo el 30 de enero de 1838 (Villanueva 2010a: 131), en el que los carlistas también fueron repelidos por las fuerzas isabelinas.

La postura de Teruel durante el proceso bélico quedó plasmada unos años más tarde por Miguel Ibáñez en su topografía médica de la ciudad: "En la primera contienda civil, y dados sus sentimientos e ideas liberales, se mantuvo fiel a la legalidad existente, y sus habitantes defendieron con las armas en la mano la causa de la libertad" (Ibáñez 1895: 12).

Tras el fin de la guerra en el norte de la península en 1839, se produjo una ofensiva a la resistencia carlista liderada por Cabrera en el Maestrazgo, lo que provocó finalmente la retirada de estos y el fin de la guerra en 1840 .

La capital turolense fue durante todo el siglo XIX el bastión del liberalismo progresista dentro de la provincia y tuvo en el nombre de Víctor Santos Pruneda Soriano (1809-1882) a su activista más conocido y punta de lanza de este movimiento. Con la revolución de 1840 concluyó la regencia de la reina María Cristina, que marcha al exilio, con lo que comenzó el periodo de la regencia del general Espartero (1840-1843), que pronto se enfrentaría con los propios liberales. Los republicanos prunedistas se levantaron en Teruel contra Espartero el 11 de junio de 1843 (Villanueva 2010b: 136), teniendo que resistir el bombardeo llevado a cabo por el brigadier Enna durante el sitio del verano de 1843, como describe Cosme Blasco en su Historia de Teruel:

[...] y por haber resistido Teruel el sitio que la puso el brigadier Enna a fines de Junio de 1843, a pesar de la gran constancia y valor con que la atacaron las tropas sitiado- 
ras, el gobierno provisional de la Nación por decreto de 11 de Setiembre de 1843, concedió a su Ayuntamiento el tratamiento de Excelencia[...] (Blasco 1870: 165)

Afortunadamente, la segunda guerra carlista (18461849) apenas afectó a Teruel. Sin embargo, el descontento político y la crisis económica que sufría el pueblo alimentó el malestar de la población en todo el país, situación que terminó por explotar en forma de revolución en 1868 — La Gloriosa—, en la que se derrocó a Isabel II, lo que daría paso al Sexenio Democrático (1868-1874), momento estelar del republicanismofederal turolense (Villanueva 2010b: 136). Al final de este paréntesis democrático se proclamó la Primera República Española, que acabó con la Restauración borbónica, en la que Alfonso XII ocuparía el trono tras el pronunciamiento del general Arsenio Martínez-Campos en Sagunto.

Durante el Sexenio Democrático comenzó la tercera guerra carlista, desarrollada entre 1872 y 1875 , en la que los carlistas se hicieron fuertes en Cantavieja, donde establecieron su capital a partir de 1873. Desde este punto fuerte intentaron la conquista de Teruel con dos ataques llevados a cabo el 3 y 4 de julio y el 4 de agosto de 1874 (Ibáñez 1895: 12-13), repelidos por la defensa de la ciudad. En el primer ataque, los sublevados lograron ocupar el Arrabal, posición desde la que simularon un ataque por tres puntos distintos, con el que llegaron a perforar la muralla cerca del corral del Roquillo, entrando en el interior, aunque la guardia civil logró cortar su incursión. Volvieron a intentar la conquista con un segundo ataque pertrechado por diez mil hombres al que la ciudad respondió de igual manera (Rújula 2014: 339-340), terminado con el momento más delicado de la guerra para Teruel, donde, pese la resistencia, la situación sería crítica.

Con la vuelta de la monarquía borbónica, se aprobó la Constitución de 1876 promulgada por Cánovas del Castillo, en la que la soberanía era compartida por el rey y las Cortes. El turno de partidos entre conservadores y liberales, que se dio a nivel nacional, se reprodujo en el gobierno de la ciudad de Teruel, en un estado de retraso y abatimiento debido, entre otros motivos, a las consecuencias de las guerras carlistas, las importantes crisis agrarias, las epidemias de cólera, la falta de un proceso de industrialización real y el haber quedado fuera de las principales líneas ferroviarias construidas en España durante las décadas de los 50 y 60, siendo en 1891 la única capital de provincia que carecía de ferrocarril (Rújula
2014: 342-343). Se había creado una gran brecha entre la España urbana en proceso de industrialización y la España agrícola (Terán 1999: 111), y Teruel, al igual que otras ciudades, se había convertido en una capital de provincia que se distinguía únicamente del medio rural, en cuanto a la incorporación a la modernización, por la acumulación de servicios derivados de su condición administrativa.

\section{UN PAISAJE URBANO CAMBIANTE: OBJETIVOS Y METODOLOGÍA}

El convulso siglo XIX produjo un gran cambio en la imagen exterior de Teruel, pues a su ya desfigurado antiguo recinto murado, del que ya no quedaba rastro en algunas zonas, se le añadieron las nuevas fortificaciones decimonónicas levantadas para la defensa de la ciudad y que apenas sobrevivirían al mismo siglo.

Atendiendo a la particularidad de este periodo tan intenso y, a la vez, tan olvidado, el objeto de la presente investigación es el de recuperar el cambiante paisaje urbano que se produjo durante estos años, que permitirá además poder contextualizar los escasos vestigios que hoy persisten.

Para el estudio de la imagen de la ciudad decimonónica, a los grabados y descripciones realizados por estudiosos y viajeros, que ya aparecen desde finales del siglo XVIII, aportando importantes datos sobre la percepción urbana, siempre con la necesaria prudencia que estos merecen, hay que añadir la aparición de la fotografía, un nuevo medio que, a partir de la segunda mitad del siglo XIX, dejó un importante legado documental que, de forma mucho más objetiva, plasmó la imagen urbana de Teruel. A través de ella se puede apreciar el exterior de la ciudad, pero también los principales espacios públicos, donde se levantaron los nuevos edificios dotacionales y residenciales que cambiaron el paisaje urbano, entre los que cabe destacar, por su innovación y singularidad, las obras modernistas de Pablo Monguió. Entre los fotógrafos profesionales y aficionados, turolenses o foráneos, que captaron interesantes instantáneas de la ciudad durante la segunda mitad del siglo XIX y principios del XX, cabe destacar a figuras como José Martínez Sánchez, Dámaso Fuertes, Frutos Moreno y Pérez, Juan de Valdivielso, Eduardo Vidal, Domingo Uriel Pascual, Juan Cabré, Francesc Xavier Parés i Bartra u Otto Wünderlich (Pérez 2013: 37-65). Además, con el inicio del siglo XIX, aparecieron las primeras 
cartografías de la ciudad, que aportan una importantísima fuente de información que ayuda a recomponer de manera más completa la imagen de la ciudad, y que en gran parte se encuentran inéditas.

Para su correcto estudio se ha procedido a la coordinación de las cartografías históricas, así como a la elaboración de diversas cartografías historiográficas del periodo ${ }^{4}$, lo que permite el correcto análisis y estudio comparativo de las planimetrías con la precisión requerida, pues la coordinación toma como base la cartografía vectorial a escala 1:500 de la ciudad actualizada en 2013 por el Ayuntamiento de Teruel (Ayuntamiento de Teruel 2013 [plano]), un levantamiento de gran precisión.

Pero el estudio de la forma urbana no se puede basar únicamente en las fuentes documentales, incompleto sin el análisis directo de la ciudad. El carácter efímero del paisaje estudiado ha dejado contados restos en la actualidad. El resto con mayor visibilidad es el remate construido durante las guerras carlistas que corona el tramo más imponente y mejor conservado de la muralla medieval, que se levanta entre la torre de la Bombardera y la torre del Agua. Tramo que afortunadamente está en proceso de restauración, con lo que se ha podido realizar un análisis in situ de la fábrica carlista, gracias a que la dirección facultativa ${ }^{5}$ de la obra nos ha facilitado el acceso, así como importantes datos sobre este singular patrimonio (Fig. 1).

\section{EL SISTEMA DEFENSIVO}

Desde la fundación de la ciudad, se le otorgó una gran importancia al sistema defensivo. Hay que considerar que la muralla no sólo tenía un sentido defensivo; a la función de delimitación jurídica o fiscal existente en casi todas las poblaciones desde la Edad Media, hay que

\footnotetext{
4 Se han elaborado cartografías historiográficas de 1811, 1869 y 1881, según una metodología que intenta garantizar el máximo rigor de las planimetrías efectuadas (Sancho 2015, 29-37).
}

\footnotetext{
5 El proyecto de restauración de este tramo de la muralla es del arquitecto José Ángel Gil, quien también es el director de las obras, facilitándonos el acceso a las mismas.
}

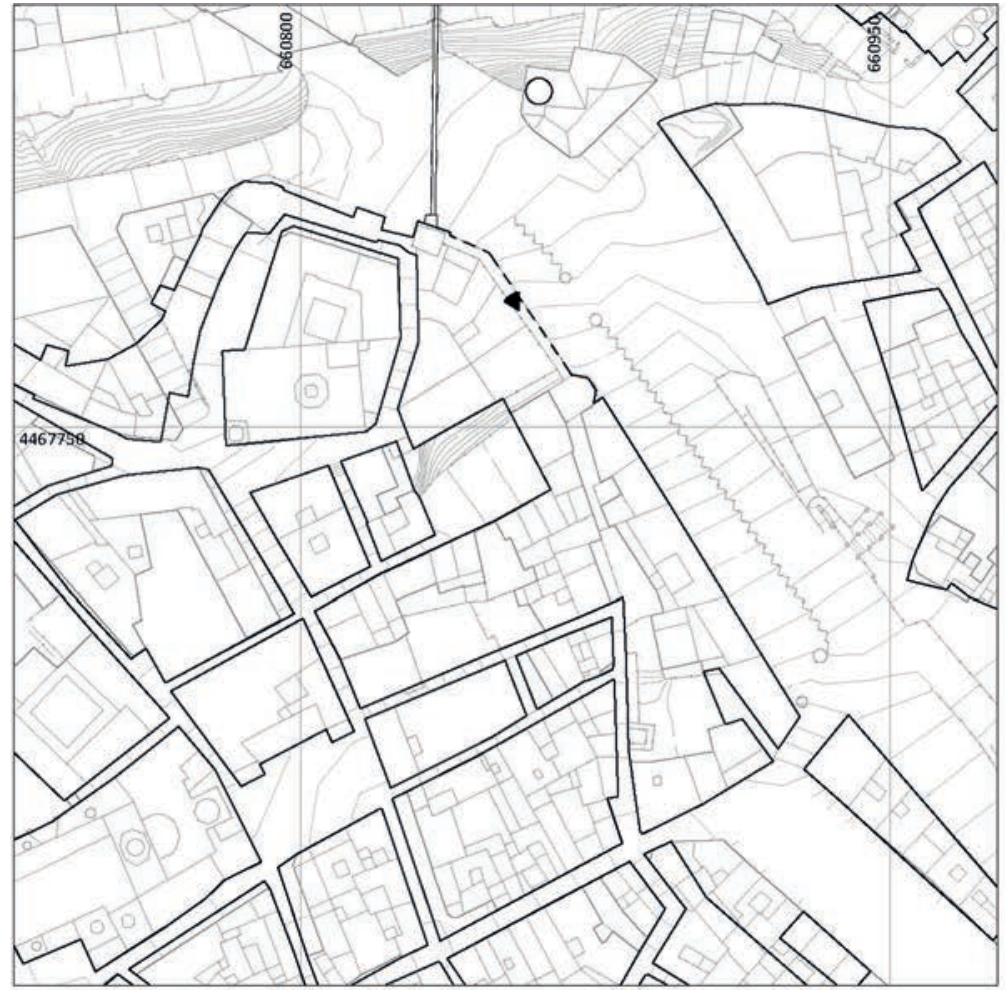

UTM ETRS89 Huso 30

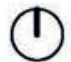

(1)

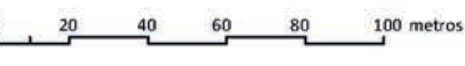

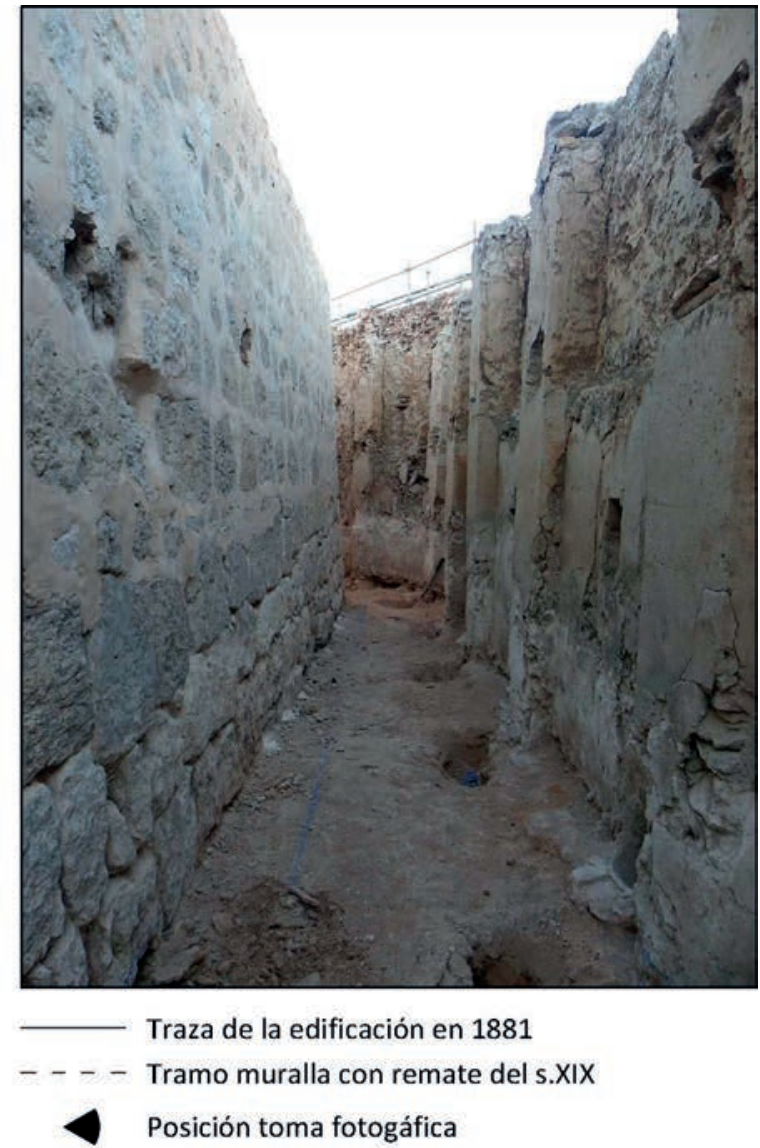

Posición toma fotogáfica

Fig. 1. Plano de Teruel con la traza de la edificación en 1881 sobre la base levantamiento cartográfico actual, ubicando el tramo de muralla con remate del s. XIX y fotografía desde el adarve. Elaboración propia. (Ayuntamiento de Teruel. 2013 [plano]). 
sumar el papel que jugó durante los siglos XVI y XVII para el control de las epidemias, al aislar la ciudad en caso de peste (Lozano 2011: 168). Sin embargo, tanto la muralla como el resto del sistema defensivo se encontraban, al comienzo del siglo XIX, en proceso de abandono, pues desde la guerra de Sucesión no había sido de utilidad para la ciudad, además de entenderse como un impedimento para la expansión y modernización del espacio urbano, por lo que fue derribada en algunas partes y tapada por la edificación en otras, aunque aún era visible en gran parte del perímetro: "Estuvo antiguamente fortificada y aún conserva sus antig. muros" (Miñano y Bedoya 1826-1828: VIII, 423).

Todo cambió con el belicoso siglo XIX, primero debido a la ocupación francesa, en los albores de la centuria, y, más tarde, se volvió a hacer necesaria la defensa de la ciudad frente a los ataques carlistas.

Durante la guerra de Independencia, el ejército francés, una vez tomada Teruel, fortificó la zona del seminario, lo que afectó a diversas construcciones, tal y como se aprecia en el plano levantado por las tropas francesas en 1811 (Ejército francés 1811 [plano]). No fue la única transformación que provocó la ocupación, ya que también se produjeron importantes cambios en muchos edificios de la ciudad ${ }^{6}$, aunque de mayor calado fueron las reformas producidas en el sistema defensivo por los conflictos posteriores. Así, como consecuencia de la primera guerra carlista, se planteó el proyecto de fortificación de la ciudad. En este punto, hay que tener en consideración que las condiciones topográficas de la ciudad habían cambiado como consecuencia del terraplenado necesario para la creación de las rondas durante el siglo XVIII y, además, tampoco se tenían los mismos requerimientos defensivos que en la Edad Media debido a la evolución de los artefactos bélicos, por lo que el proyecto de fortificación planteado no trataba únicamente de reforzar y reconstruir el sistema defensivo existente, sino que fue planteado desde el punto de vista de las nuevas necesidades militares.

Se planteó la formación del antiguo recinto, así como aspillerar las casas que formaban parte de él, mientras que el seminario sería utilizado como ciudadela o casa fuerte, ubicado al norte de la muela. Además

\footnotetext{
6 Sobre el proyecto de fortificación del Seminario, así como sobre la ocupación y consecuencias en otras edificaciones debido a los distintos periodos bélicos y las nuevas ideas imperantes, se profundizará más adelante al hablar de las transformaciones sufridas por los edificios de las órdenes religiosas.
}

de este, otros edificios tendrían especial importancia en la defensa de la ciudad, como el convento de Carmelitas, situado al oeste, en la parte alta de la calle San Francisco, calle en pendiente que daba acceso al núcleo urbano. Se proyectó un nuevo trazado previo a la primitiva muralla, que circundaba la ciudad, con tres baluartes: el de la Reina Gobernadora, en el sur, sobre el Espolón; el de la Nevera, en el noreste, bajo los Arcos; y el de Ambeles, junto a la torre de mismo nombre; además de un foso en la zona noreste, menos escarpada. También, se proyectó una caponera desde el seminario hasta el rio, de tal forma que se diseñó un sistema fortificado mixto, en el que se combinaba la utilización de baluartes, ya en decadencia (Clairac y Saénz 1884: III, 159), con la de una caponera, que había demostrado ser más eficaz para la defensa de los ángulos muertos, con la ventaja de requerir un trazado de muralla más sencillo y, por lo tanto, una ejecución más rápida que el tradicional sistema abaluartado (Fig. 2).

En el Croquis de Teruel y sus inmediaciones, firmado en 1835 (CEME 1835 [plano]), se plasmó el trazado del sistema de fortificación, del que gran parte ya se había realizado para la citada fecha, pues las partes concluidas se representan en carmín, mientras que las delineadas en amarillo estarían aún sin construirse. Lo más significativo de este plano es que se plantea la inclusión del puente de Isabel II en el sistema fortificado, con un reducto en la cabeza del puente, situado en los montes de las Cuevas. El proyecto del puente de Isabel II fue redactado el mismo año de $1835^{7}$ pero, debido a falta de fondos, a mediados de siglo aún no se había concluido, tal y como apunta Pascual Madoz: "El de Isabel II empezóse á levantar en 1835 con el objeto de unir la c. al llano de San Cristóbal, cruzando el barranco de los Arcos. Se halla paralizada la obra por falta de fondos, habiéndose construido únicamente los dos machones" (Madoz 1849: XIV, 744).

Con lo que este no quedó incluido dentro del recinto fortificado, tal y como se puede observar en los siguientes proyectos de fortificación de la ciudad. No obstante, para dar servicio al puente, también llamado de Pierrad, y aprovechando que estaban levantados los dos machones, se construyó un tablero con estructura de madera, tal y como lo describe en 1870 Cosme Blasco al hablar de los distintos puentes existentes en Teruel:

Fecha del plano del proyecto (Miguel y Polo 1835 [plano]). 


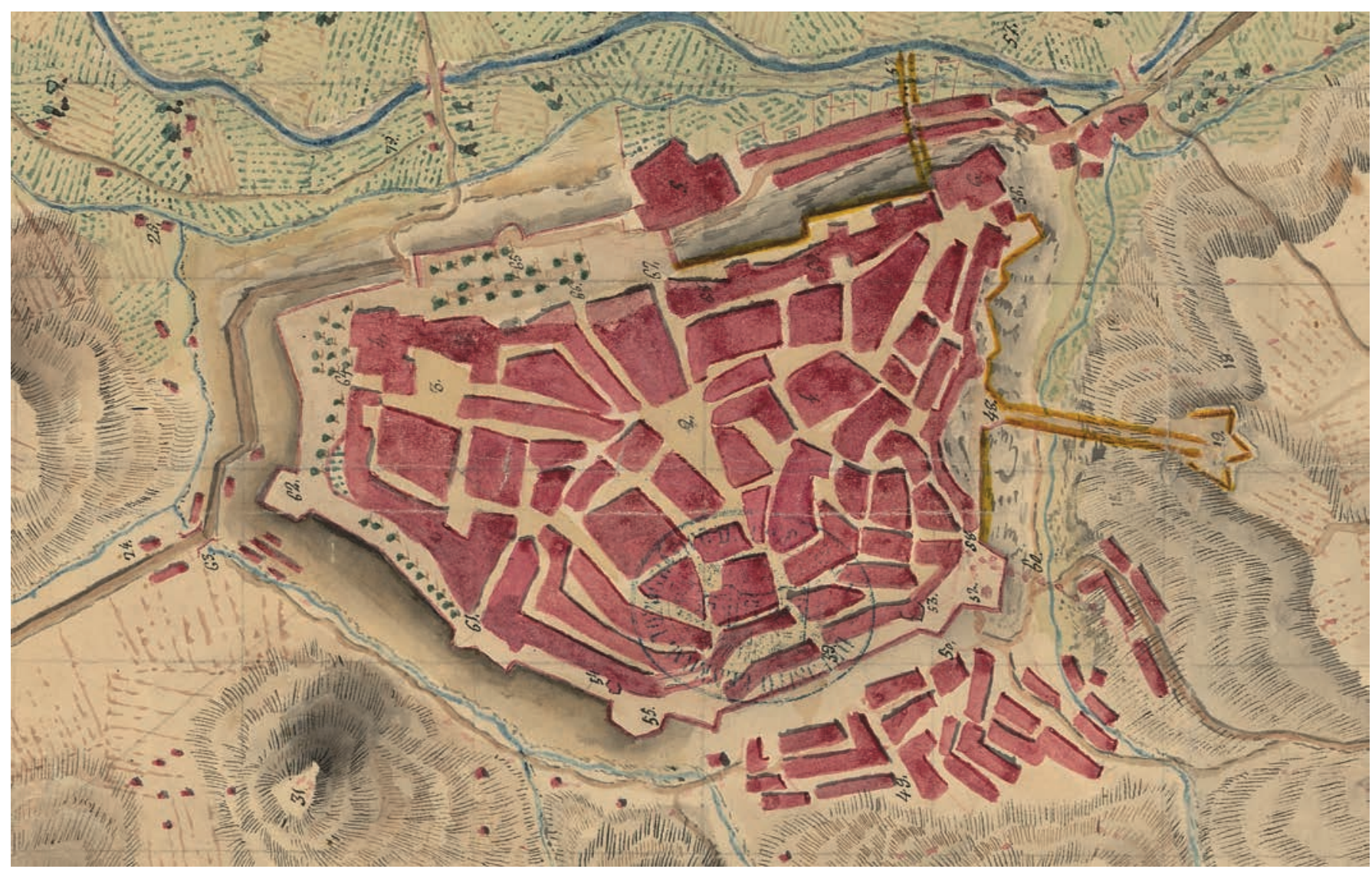

Fig. 2. Detalle del Croquis de Teruel y sus inmediaciones, 1835. Nota: rotado respecto al original, con el norte orientado hacia la derecha (CEME 1835 [plano]).

Sobre el rio Turia se encuentra, siguiendo la corriente un hermoso y sólido puente de hierro, obra que data del año 1867, sirviendo de paso á la carretera de Cuenca, y mas abajo hay otro llamado de Tablas: también debajo de los Arcos hay otro puente de madera denominado de la Reina, por el que pasa la carretera de Alcañiz" (Blasco 1870: 102)

Esta estructura fue quemada la mañana del 4 de julio de $1874^{8}$ con motivo de la tercera guerra carlista, como medida de defensa. Tras este suceso quedó con el aspecto que aparece en una fotografía de la época donde se observan distintos elementos de la fortificación de la ciudad (Fig. 3).

No sería hasta 1885 cuando se adjudicaron las obras para la terminación del puente, lo que se anunció en la prensa local: "La subasta para la construcción del puente de la Reina, cuyo proyecto hizo el Sr. D. Alejandro

8 El turolense: Avisos, noticias, anuncios e intereses materiales. Año III, Núm. 155. Teruel, 01 de noviembre de 1878, p. 3. / La crónica: periódico conservador y de intereses generales de la provincia de Teruel. Año II, Núm. 160. Teruel, 22 de julio de 1883, p. 3.
Mendizábal en el mes de febrero de este año, ha sido adjudicada á D. Pablo Pedroso, debiendo dar principio á las obras en un plazo muy próximo". Y un año más tarde estaba concluido, así lo nombraría Valverde en 1886 (Valverde y Álvarez 1886: 89).

En el Plano del Proyecto de la Fortificación de Teruel de 1838 (CEME ca. 1838 [plano]), se utiliza el mismo convenio gráfico, en relación con lo que se encontraba construido y lo que no, que en el de 1835, aunque con mayores matices. Se trata de un documento cartográfico ya más preciso y de mayor escala, donde se pueden apreciar los detalles del sistema defensivo, cuyo esquema general coincide con el croquis de 1835 , aunque ya no se incluye el puente de Isabel II dentro del recinto amurallado. Además, ya no se define únicamente el trazado, sino que se delinea también el perfil, distinguiéndose los dos elementos principales de cualquier obra de fortificación (Clariac y Saénz 1884: III, 156). Existen dos tipos de secciones, una para el foso, en la zona noreste, y otra para las zonas que se

\footnotetext{
Revista del Turia. Año I, Núm. 14. Teruel, 15 de septiembre de 1885, p. 7.
} 


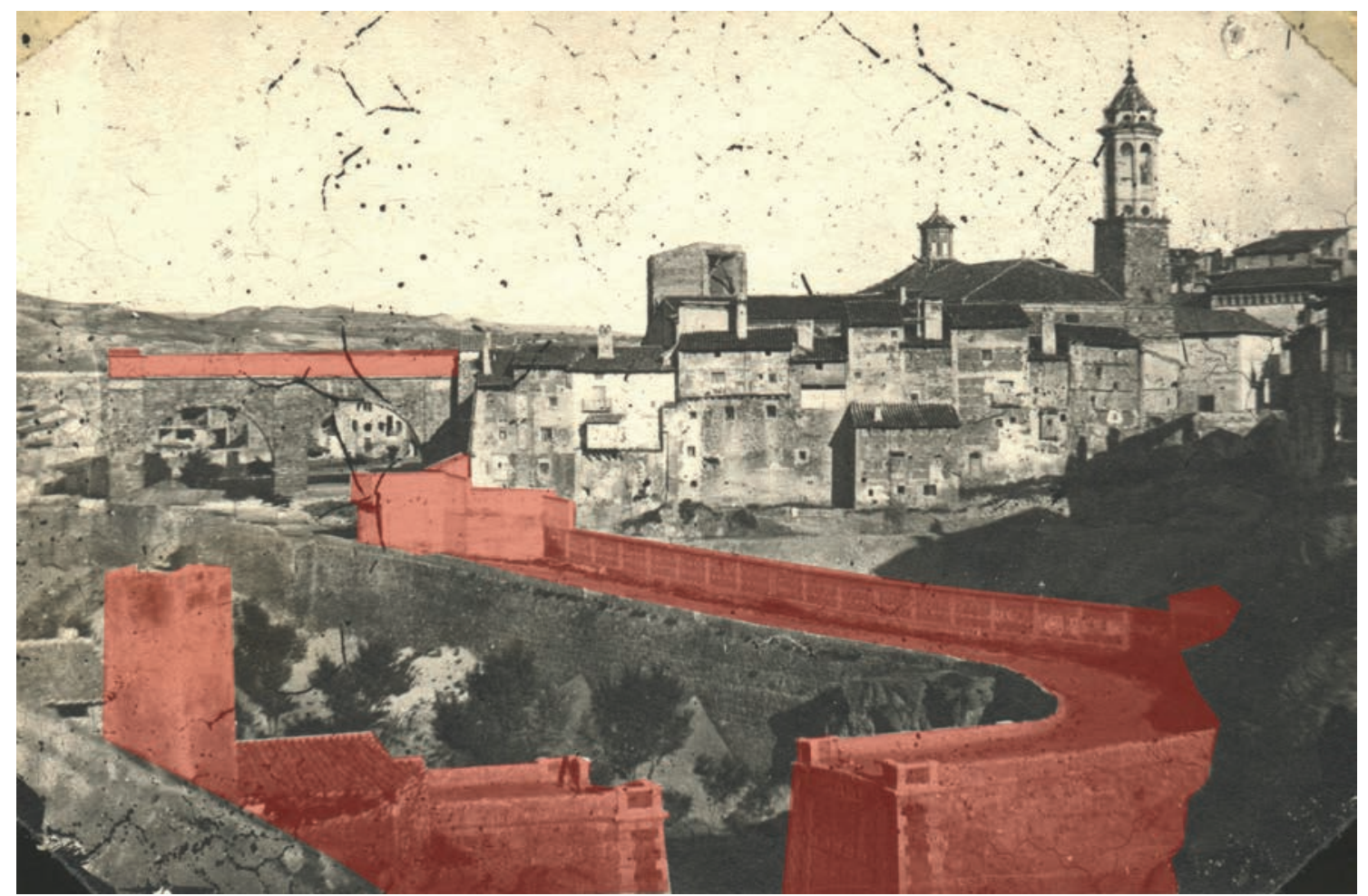

Fig. 3. Fotomontaje resaltando elementos de una fotografía del siglo XIX, cornisa norte. Elaboración propia / Archivo fotográfico de Antonio Pérez.

sitúan sobre elevadas o inaccesibles, donde no se plantea la construcción de foso, puesto que por la propia topografía no era necesario. El flanqueo del foso se resuelve mediante el trazado de los baluartes entre los que se ubica.

En la parte derecha del plano se incluye un texto explicativo en el que se especifica, en su punto cuarto, que la calle San Francisco y la parte del Arrabal representada en el plano, así como otras edificaciones contiguas a las obras, deberían demolerse al menor recelo de ataque, y, en el punto quinto, que en este caso el convento de Carmelitas debería ocuparse y sostenerse hasta el último extremo, lo que denota la importancia dada a esta edificación dentro del sistema defensivo (Fig. 4).

Aunque en este proyecto no aparezcan detallados, gracias a los planos de 1835 y 1840 (CEME ca. 1840 [plano]) parece que este recinto contaba con cuatro accesos, el situado más al sur se ubicó en el paseo del Ovalo, al que se accedía desde el camino de Valencia; otro en el este comunicando con el Arrabal como continuación del Tozal, y que según una cartografía de 1842 (Campuzano, J. J. 1842 [plano]) se accedía a través de un puente levadizo que salvaba el foso defensivo; en el oeste al subir la calle de San Francisco, se situó otro acceso junto al convento de Carmelitas y, por último, en el norte la puerta de Daroca o de la Andaquilla, que sería la única que coincidía con una de las siete puertas del recinto fortificado levantado en la Edad Media que, aunque la mayoría estaban muy modificadas, aún subsistían pues aparecen citadas tanto en el plano de 1835 como en el de 1838 (CEME ca. 1838 [plano]) (Figs. 2, 4 y 5).

En cuanto a las mencionadas puertas del antiguo recinto, de las siete existentes alrededor de 1838, en 1870 ya sólo se citan tres (Blasco 1870: 160): la de San Salvador - Puerta de Guadalaviar-, que ya no tenía su configuración medieval, pues se había derribado, por lo menos parcialmente, en 1764, con lo que sería una reconstrucción posterior o parte de la antigua, que no contaba con torres, a diferencia de su antecesora; la de la Andaquilla y la de la Traición — puerta de San Miguel-, mientras que Miguel Ibáñez publica al final del siglo XIX que ya sólo quedan dos, la de la Andaquilla y la de la Traición o San Miguel, puntualizando que el resto habían desaparecido con las nuevas construcciones que cambiarían completamente el aspecto de las zonas donde se ubicaban (Ibáñez 1895: 64) (Fig. 6). 


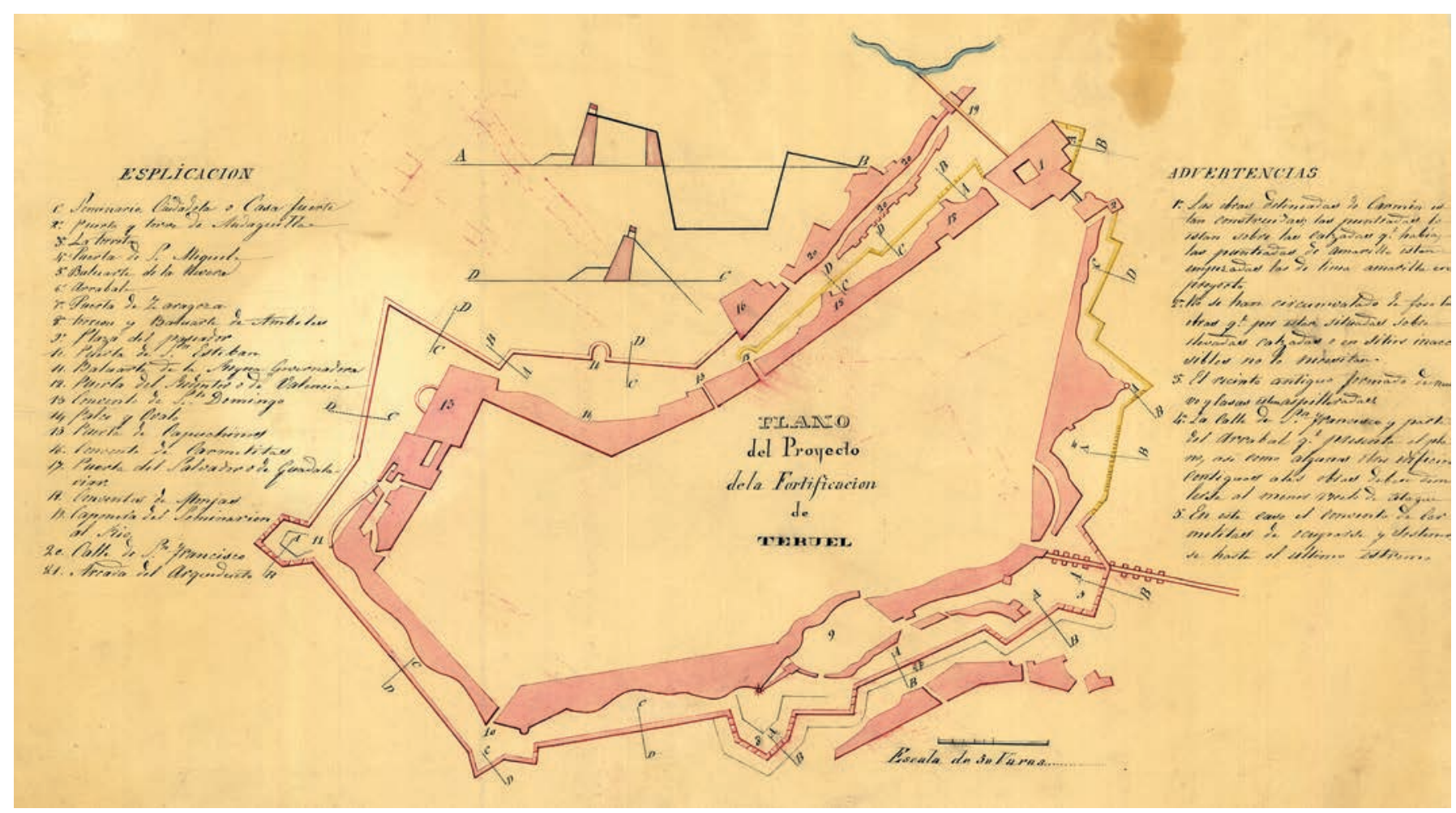

Fig. 4. Plano del proyecto de la fortificación de Teruel (ca.1838). (CEME ca. 1838 [plano]).

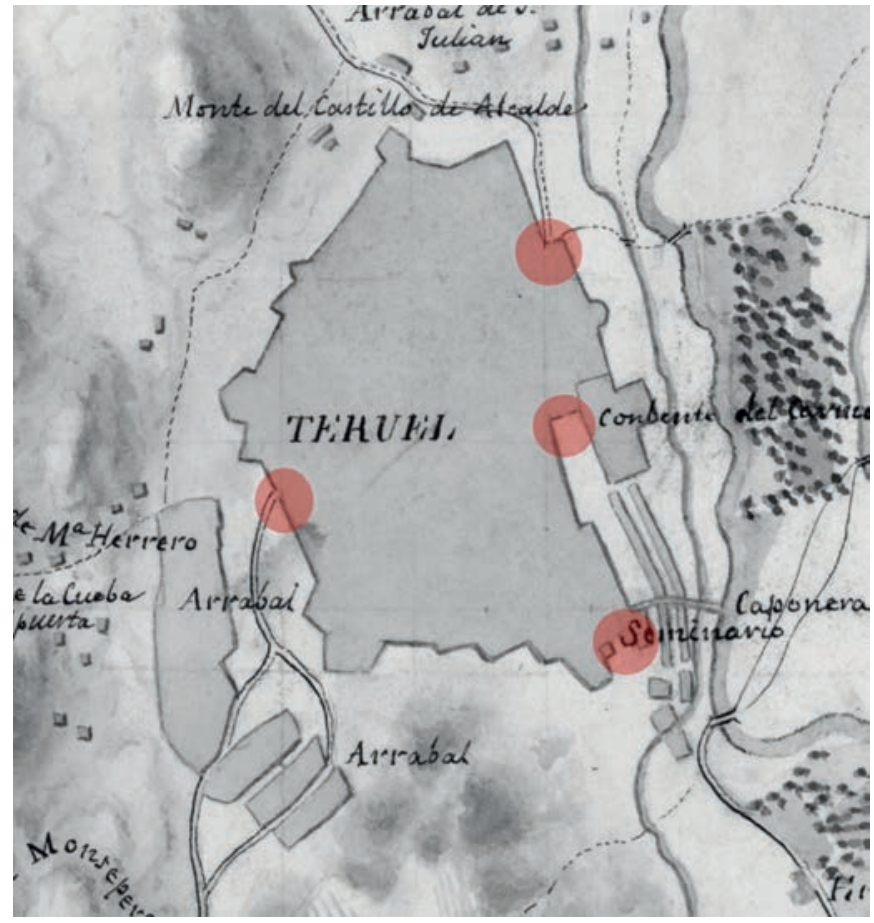

Tras la primera guerra carlista se continuó ocultando la muralla medieval, edificando por la parte exterior de esta en la parte noreste y este del perímetro (Ibáñez 1895: 64), así, a mediados de siglo, Madoz dice que aún se apreciaba la muralla a partir del Gobierno Civil hacia
Fig. 5. Montaje destacando los accesos al recinto fortificado sobre plano editado alrededor de 1840. Nota: el norte orientado hacia la abajo. Elaboración propia. (CEME ca. 1840 [plano]).

el norte (Madoz 1849: XIV, 742), y Pruneda en 1866 especifica que ya son escasos los restos, a excepción de un trozo junto a la puerta de San Esteban, y los dos torreones llamados castillo de Ambéles y torre Lombardera (Pruneda 1866: 33). 


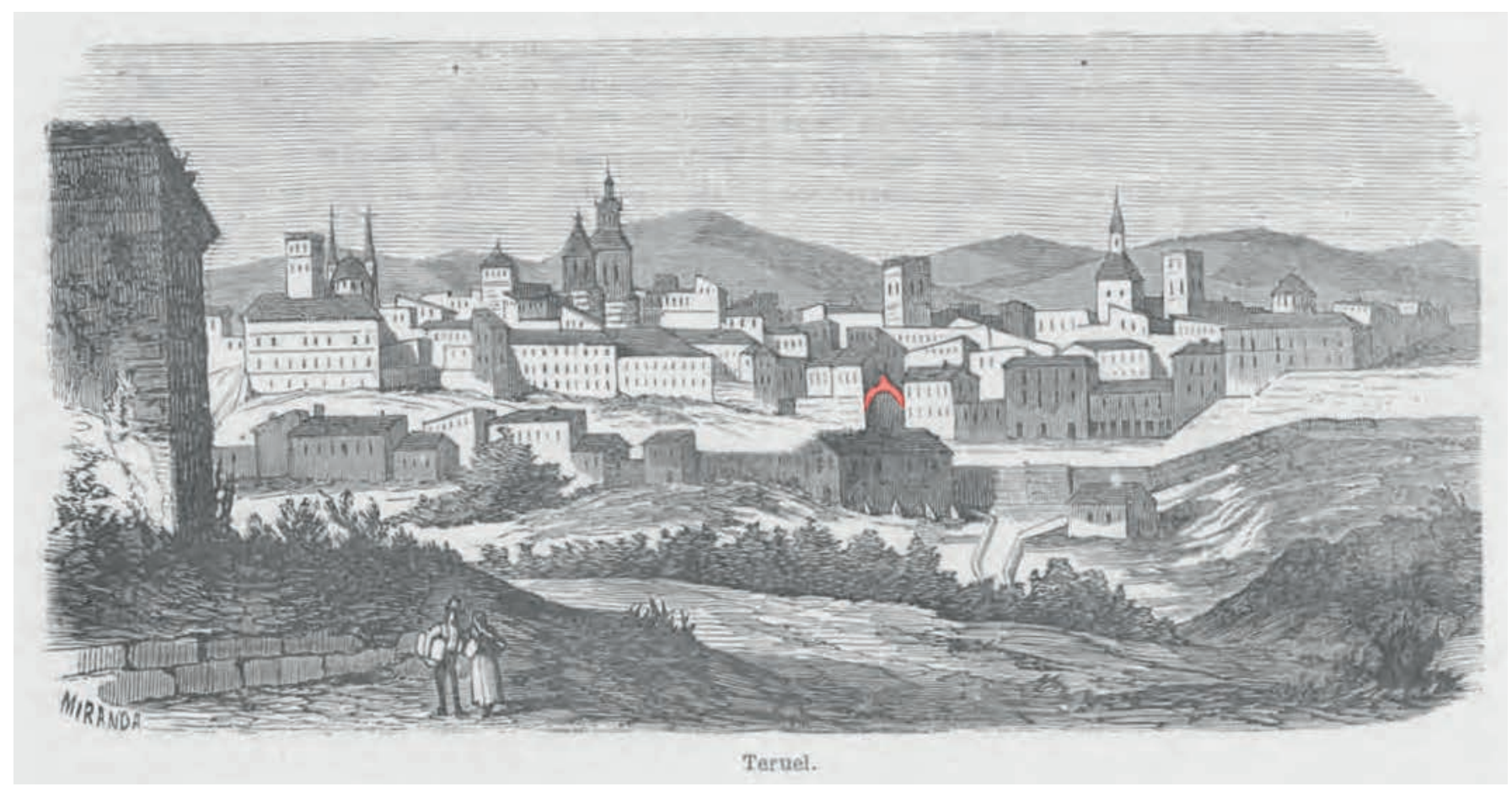

Fig. 6. Fotomontaje resaltando la puerta de San Salvador sobre grabado de Miranda publicado en 1866, cornisa oeste. Elaboración propia. (Pruneda 1866: p. 33).

Una vida más efímera tendría la nueva fortificación, que, levantada con motivo de la primera guerra carlista, gran parte de ella no debió de sobrevivir hasta la tercera guerra carlista, tres décadas más tarde. Su estado de conservación a mediados de siglo no era muy bueno, tal y como describe Madoz:

Penétrase en ella por siete puertas que tienen los débiles $\mathrm{y}$ vetustos muros que la ciñen, cuyo contorno es una forma irregular, siendo su construcción de tabiques de medio pie de espesor con sus aspilleras correspondientes y esplanadas en los ángulos salientes, que por ellos se comunica a otra parte de la fortificación interior que es lo que llama muro. Este es de una mampostería de bastante espesor y solidez, sobre el cual se han construido casas de habitación (Madoz 1849: XIV, 739).

Pues, hay que tener en cuenta que, la mayoría de estas obras no estaban pensadas para ir más allá del propio conflicto. De hecho, cuando en 1870 Cosme Blasco realiza una minuciosa descripción de la ciudad, al hablar de la muralla se centra en la medieval, y sólo en un párrafo hace referencia a lo que parece tratarse de una fortificación de la primera guerra carlista:

Entre O. y N. existe otro cuadrado, y fundado sobre un peñasco, constituye parte de la muralla, siendo el contorno de esta de forma irregular, su construcción de tabiques de medio pie de espesor con sus aspilleras correspondientes, y esplanadas en los ángulos salientes, por los cuales se comunica a otra parte de la fortificación interior que se llama muro (Blasco 1870: 159).

En 1873 los periódicos editados en la capital de España, se hicieron eco de la fortificación de Teruel: "La población de Teruel está ya fortificada, y un muro de circunvalación rodea aquella capital" ${ }^{10}$. Esta fortificación, que debió reconstruir y emular, en gran medida, a la levantada con motivo la primera guerra carlista, se puede observar en algunas fotografías existentes de aquel periodo. En ellas queda reflejada la distinta traza del lienzo exterior en la zona norte de la ciudad, que pasó de circundar la ronda, tal y como se plasma en los planos de fortificación de la primera guerra carlista, a dejar la calle Miguel Ibáñez fuera del recinto, pues se levantó sobre el límite del corral de Roquillo ${ }^{11}$ (Figs. 3 y 7).

\footnotetext{
10 El Imparcial: diario liberal. Año VII., Núm. 2275. Madrid, 18 de septiembre 1873, p. 3. / El Pensamiento español: diario católico, apostólico, romano. Año XIV., Núm. 4158. Madrid, 18 de septiembre 1873, p. 2. / La Nación: diario político y literario de la tarde. Núm. 2507. Madrid, 18 de septiembre 1873 , p. 3.

11 Véase figura 2.
} 


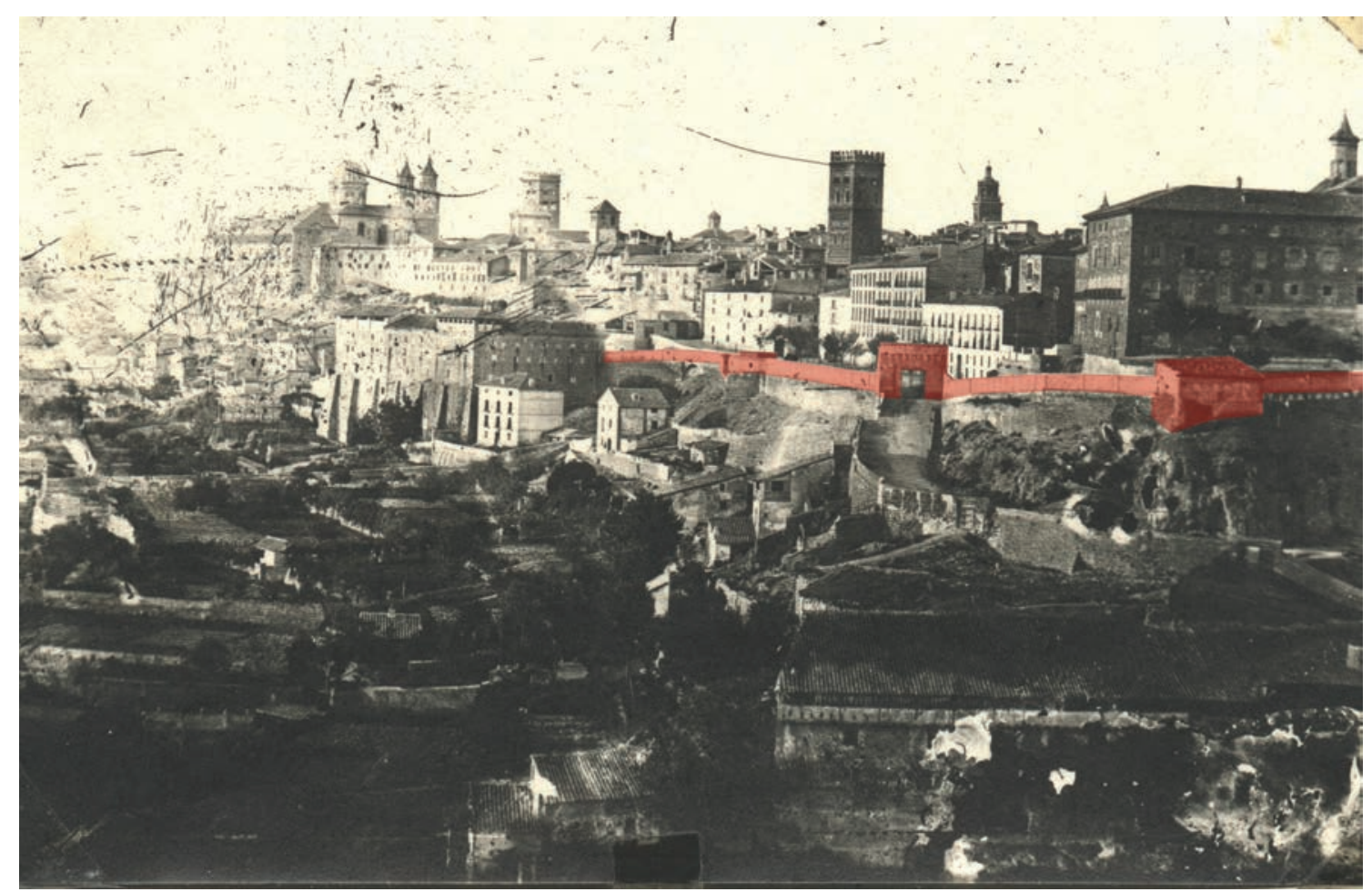

Fig. 7: Fotomontaje resaltando elementos de una fotografía del siglo XIX, cornisa suroeste. Elaboración propia. Archivo fotográfico de Antonio Pérez.

El nuevo lienzo exterior se materializó mediante una tapia reforzada por pilares cada cuatro metros, y tres o cuatro aspilleras para fusilería por paño (Pérez 2014: 513), y se recreció la antigua muralla en algunos tramos estratégicos con un sistema similar al empleado en el lienzo exterior, pero con una métrica algo distinta. En el tramo comprendido entre el portal de San Miguel y la torre de la Lombardera, el recrecido se realizó mediante tapia de yeso con aljezones y otros materiales de relleno, encofrado con enlistonado vertical, con un espesor que varía de los $24 \mathrm{~cm}$ en la base a $14 \mathrm{~cm}$ en coronación, reforzado con pilastras, de base cuadradas y 50 centímetros de lado, con un intereje algo variable de aproximadamente dos metros, y con una o dos aspilleras por paño ${ }^{12}$. En este tramo se forjó y se cubrió el espacio existente entre el nuevo lienzo, en el exterior, y el recrecimiento de la muralla realizado como consecuencia de la traída de aguas a la ciudad en el siglo XVI, en el lado interior. Este espacio conectaba con la torre del agua, donde termina el acueducto de Los Arcos. Sobre esta torre y sobre la tercera pilastra del acueducto se levantaron sendas garitas, cuyo paso se protegió con un parapeto que unía ambas construcciones.

\footnotetext{
12 Estos datos han podido ser recopilados gracias a las obras de restauración de este tramo de la muralla llevadas a cabo por el arquitecto José Ángel Gil.
}

Al igual que las citadas garitas, se dispusieron otros elementos singulares: construcciones fortificadas dispuestas en el perímetro del recinto, como la situada junto al corral de Roquillo; o una puerta de considerables dimensiones que daba acceso al recinto por el paseo del Óvalo, desde la carretera de Valencia.

Entre ambos trazados, el de la muralla medieval y el nuevo lienzo, quedaron encerrados los paseos y alamedas, que surgirían en el siglo XVIII como extramuros, circundando gran parte del núcleo urbano, como alivio de una ciudad encerrada por sus murallas. Unos espacios que cambiarían su uso lúdico, de esparcimiento, por el de formar parte del sistema defensivo en época de guerra. Un espacio que dotó a la fortificación de una mayor funcionalidad, adaptándose a los requisitos marcados por la nueva artillería, con mayor espacio de carga y maniobra (Fig. 8).

Este nuevo sistema defensivo apenas sobrepasará los albores del siglo XX, ya que existen documentos gráficos ${ }^{13}$, de sólo unos años más tarde del final de la tercera guerra carlista, que atestiguan como se iría arruinando el nuevo recinto murado. Se tiene

\footnotetext{
Fotografía datada alrededor de 1889 en los archivos del Instituto de Estudios Turolenses (Otra vista de Teruel, Frutos Moreno. Archivo Dosset, Instituto de Estudios Turolenses).
} 


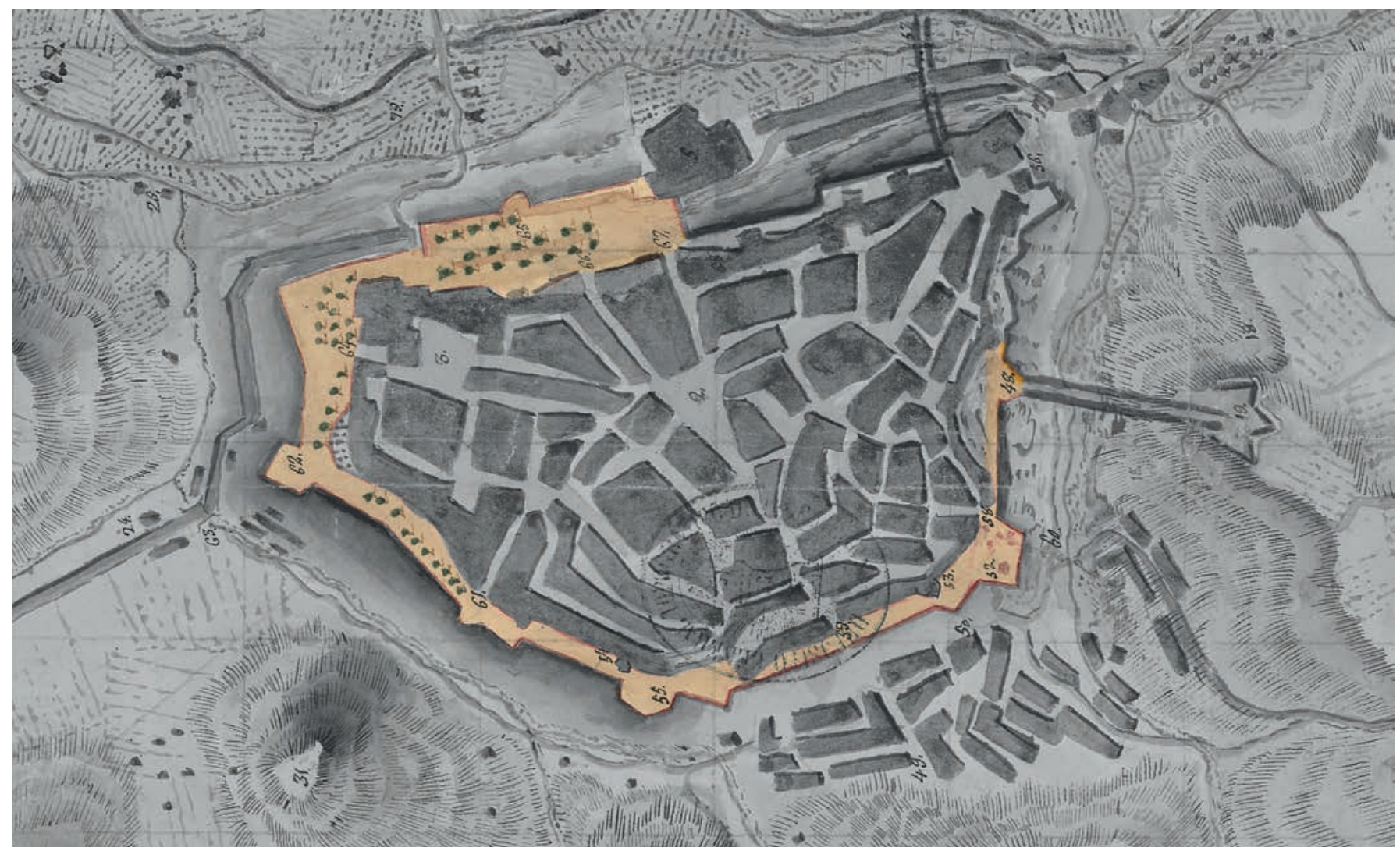

Fig. 8. Montaje destacando el espacio de paseos y alamedas entre murallas en la primera guerra carlista sobre detalle de plano de Teruel de 1835. Nota: rotado respecto al original, con el norte orientado hacia la derecha. Elaboración propia. (CEME 1835 [plano]).

constancia que en el Óvalo el derribo de la muralla comenzó el 6 de junio de $1877^{14}$. Además, en las fotografías de principio de siglo, ya no se aprecia ni rastro de este nuevo trazado en la mayor parte del recinto. Sólo en los lugares de peor acceso se conservaron restos de este periodo, de tal forma que en la actualidad se vislumbran contados vestigios: en el lienzo que va del portal de San Miguel a la torre de la Bombardera, actualmente en proceso de restauración, y en la parte posterior de algunas casas de la calle Andaquilla, quedan recrecidos realizados en esta época sobre el muro medieval ${ }^{15}$. De igual manera, existía un importante tramo en la ronda Miguel Ibáñez con remate aspillerado de época carlista, que se perdió junto con la muralla medieval sobre la que se asentaba, en un desgraciado suceso que tuvo lugar en 2001 (Ibáñez 2010: 328). Por el contrario, el tramo que se encuentra en restauración se va a consolidar y reforzar, para garantizar su

\footnotetext{
14 El turolense: Avisos, noticias, anuncios e intereses materiales. Año II, Núm. 146. Teruel, 8 de junio de 1877, p. 3.

15 El muro medieval sufriría reformas durante la Edad Moderna como las realizadas como consecuencia de la traída de aguas a la ciudad en el siglo XVI.
}

permanencia, respetando también las heridas causadas por la fusilería, tanto de la guerra carlista como de la última guerra civil, con el fin de preservar la memoria de lo allí ocurrido ${ }^{16}$ (Fig. 9).

\section{LA TRANSFORMACIÓN CONVENTUAL}

Durante el siglo XIX se produjo un proceso de transformación funcional y constructivo en las edificaciones que hasta ahora habían pertenecido a las distintas órdenes religiosas. Este proceso se inició al comienzo de la centuria, como consecuencia de la guerra de Independencia, pero se acentuó con las distintas medidas legales promulgadas durante este siglo, encaminadas a enajenar los bienes eclesiásticos. Durante la ocupación francesa, en el año 1809, José Bonaparte ordenó la supresión de las órdenes religiosas en España (Esteban 2014: 40), a raíz de lo que se utilizarían muchos conventos como cuarteles militares. Una vez expulsadas

\footnotetext{
16 Entrevista a José Ángel Gil, arquitecto redactor del proyecto de restauración y director de las obras.
} 


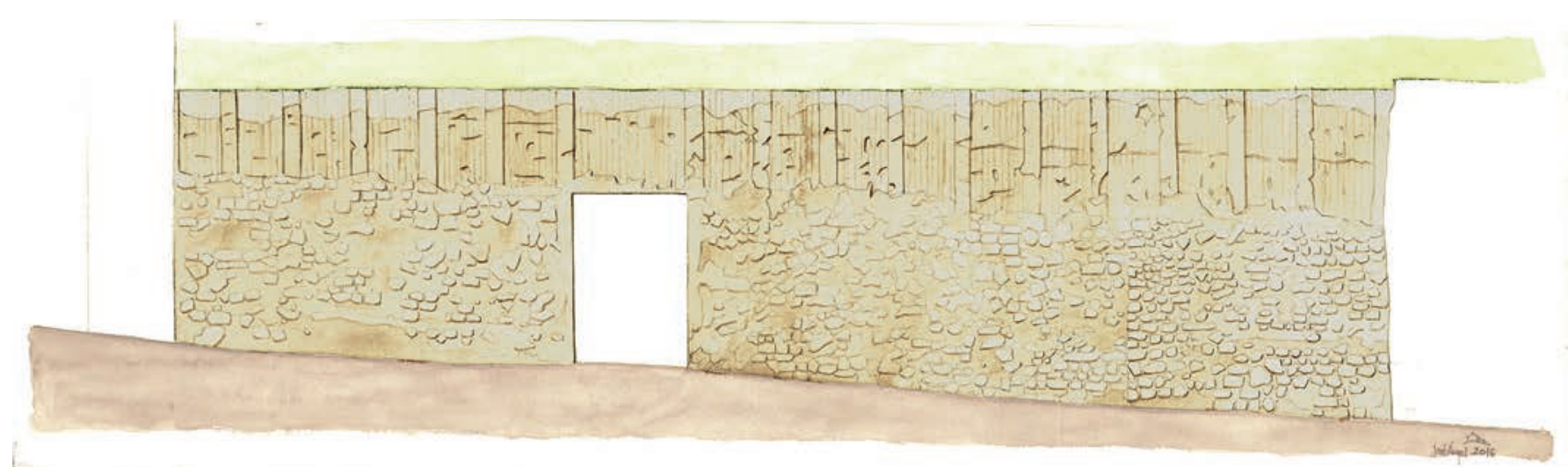

Fig. 9: Alzado del proyecto de restauración de la muralla de Teruel, en el que se puede ver el cuerpo carlista con la reparación, recrecido y regularización de la coronación. Dibujo realizado por el arquitecto José Ángel Gil.

las fuerzas invasoras, continuaron, de forma intermitente, las medidas encaminadas a disminuir el poder y privar de sus bienes a las enriquecidas órdenes, como forma de incrementar los ingresos de las arcas del Estado. Con ese espíritu, se promulgó la desamortización de 1820, durante el Trienio Liberal; la de Mendizábal, en 1836; la de Espartero, en 1841; o la de Madoz, en 1855.

El convento de la Trinidad quedó arruinado durante la guerra de Independencia, por lo que fue representado en 1811 como escombros en un plano de fortificación del seminario levantado por los franceses. Pero debió reconstruirse, por lo menos en parte, o no ser enteramente derrumbado, ya que en la desamortización de 1836 fue expoliado y vendido (Esteban 2014: 121), momento a partir del cual fue destinado a distintos usos públicos: en 1845 , se inauguró el primer instituto de segunda enseñanza de la ciudad en el piso principal, la iglesia y sacristía del ex-convento, que en 1848 se trasladó a la Casa de la Comunidad (Novella 1988: 119-121); el año siguiente, el ex-convento se destinaría a escuelas públicas (Madoz 1849: XIV, 742) y, posteriormente, a cárcel. Parece que, según lo manifestado por Miguel Ibáñez, el edificio se encontraría en un estado muy precario a final del siglo XIX:

Las cárceles de Partido, de Audiencia y Correccional, ocupan parte del ex-convento de Trinitarios, situado en el extremo Nor-Noroeste de la población. Ni la solidez del edificio, ni su capacidad corresponden al objeto a que está destinado. Las prisiones de todas clases, además de ser en muy corto número son muy pequeñas, bajas de techo, y húmedas la mayoría (Ibáñez 1895: 73).
Aún mantuvo el uso de cárcel durante los comienzos del siglo $\mathrm{XX}^{17}$. Finalmente, el edificio fue destruido durante la guerra civil de 1936.

Junto al emplazamiento del convento de Trinitarios se ubicaba el seminario conciliar, que, utilizado como plaza fuerte por los franceses, fue fortificado, adicionando elementos y derribando las edificaciones anexas del convento de la Trinidad y parte del de las monjas de Santa Clara para conseguir su aislamiento ${ }^{18}$. La torre de San Martín también se utilizó como parte del conjunto defensivo, a la cual se le practicó un nuevo vano en su lado suroeste, pudiendo así acceder a la misma a través de un patio cercado, que ocupaba el lado norte de la futura plaza del Seminario. Desde este patio se accedía también a la torre-puerta de la Andaquilla que actuaba como bastión del recinto y control de acceso a la ciudad (Fig. 10).

En 1815 el edificio del seminario fue reparado por el obispo Felipe Montoya Díez (Sebastián 1963: 107), pero su privilegiada posición hizo que repetidamente se utilizara como baluarte defensivo de la ciudad. En el proyecto para la fortificación de Teruel, realizado durante la primera guerra carlista, consta como ciudadela o casa fuerte. Tras el conflicto, en el año 1849, según Madoz, el interior del edificio estaba muy deteriorado y servía de cuartel a una pequeña guarnición y a los quintos de la ciudad y la provincia (Madoz 1849: XIV, 742), y en un plano levantado en 1850 (Ortiz De Pinedo 1850

\footnotetext{
17 En el plano de Teruel editado por A. Martín Editor de las primeras décadas del siglo XX (Martín ca. 1914 [plano]) o el plano de 1912 levantado por el Instituto Geográfico y Estadístico (DGIGE 1912 [plano]) se especifica el uso de cárcel.

18 Gazeta de la Regencia de España e Indias, n 53, 20 de abril de 1811, p. 409.
} 


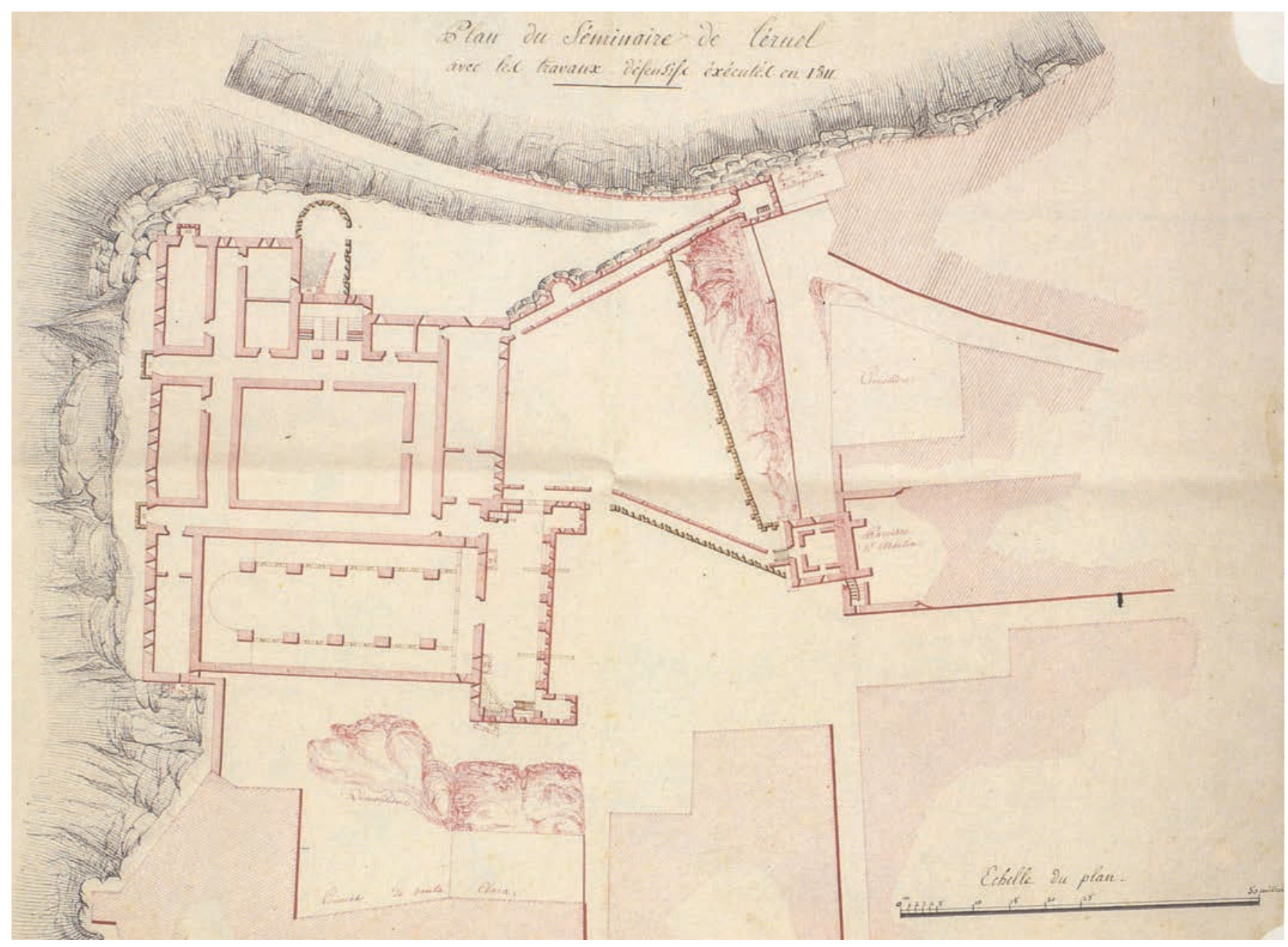

Fig. 10. Plano de las fortificaciones francesas en la plaza del Seminario, 1811 (Ejército Francés 1811 [plano]).

[plano]) por la Comandancia de Ingenieros de Zaragoza, se especifica el uso compartido del edificio por los seminaristas y la tropa, contemplando accesos diferenciados para ambas funciones. Cosme Blasco, en 1870, ratifica que la mitad del edificio se usaba como cuartel de infantería (Blasco 1870: 143).

Tras la tercera guerra carlista, en 1877 , fue convertido en Real Seminario de la Purísima Concepción y de Santo Toribio de Mogrovejo por el obispo Francisco de Paula Moreno (Sebastián 1963: 107). Pero volvió a ser bastión defensivo de la ciudad durante la fatídica guerra de 1936, en la que fue destruido.

El convento de Capuchinos, que estaba situado en el paseo del Óvalo, fue demolido durante la guerra de Independencia (Madoz 1849: XIV, 742), por lo que se trasladó a la Villa Vieja tras la ocupación:

Casi al O. está el ex-conv. de capuchinos. Fue en los primitivos tiempos ermita de Ntra. Sra. de Villavieja,
Virgen aparecida, después casa de corrección ecl.; y últimamente de la congregación de la Sangre, la que cedió el edificio á los frailes, concluida la guerra de la Independencia, y á cuya propiedad ha vuelto desde la supresion (Madoz 1849: XIV, 744).

En la desamortización de Madoz, se alude al Convento de la Villa Vieja, tasándolo en 315.000 reales, lo que supuso el fin del Convento de Padres Capuchinos en Teruel, aunque el edificio fue reutilizado, posteriormente, por los Padres Paules, que en 1936 se trasladaron a Alcorisa (Esteban 2014: 42-43).

Los frailes del convento de Carmelitas Descalzos fueron expulsados de su edificio durante la ocupación francesa, con lo que dicha construcción sufrió un grave deterioro, tanto en su fábrica como en su contenido. Tras la marcha de los galos, el 11 de junio de 1814 (Esteban 2014: 166), los frailes volvieron a hacerse cargo del convento, del que reconstruyeron su iglesia. En la 
desamortización de Mendizábal, en la que se suprimieron todos los conventos religiosos de varones, salió a subasta pública, junto con los bienes que poseía (Esteban 2014: 168). En 1842, el convento de Carmelitas alojó el cuartel de fusileros, junto a la puerta de la iglesia, y en el piso superior las cárceles públicas de la ciudad y partido (Madoz 1849: XIV, 742). Tres años más tarde, el Cuerpo de Ingenieros del Ejército redactó un proyecto para adaptar el convento al único uso de cuartel ${ }^{19}$.

En 1870, ya no existía la iglesia del convento, ya que según Cosme Blasco fue:

[...] destruido este convento después de la fatal guerra civil, fue demolida su Iglesia por donde hoy pasa la carretera de Zaragoza, y el resto del edificio se destinó a cuartel de la tropa que guarece la ciudad: ahora está convertido en graneros desde los sucesos de 1868, y la guarnición ocupa parte del Seminario (Blasco 1870: 140).

Pronto volvió a funcionar como cuartel, tal y como queda reflejado por Miguel Ibáñez, quien apuntaba que este uso se venía realizando desde años atrás: "El exconvento de Carmelitas, sólido y grande edificio, emplazado a la entrada de la calle de San Francisco, con magníficas vistas a la vega, está habilitado hace muchos años para cuartel, puede contener hasta mil plazas" (Ibáñez 1895: 73).

Lo que queda corroborado por el plano de la ciudad de Teruel editado en 1881 (CEME 1881 [plano]), donde también se especifica el uso de Cuartel de Infantería, que continuó ocupando el edificio hasta el siglo XX, como se puede observar en el plano de Teruel editado por A. Martín - editor de las primeras décadas del siglo XX—, o en el plano de 1912, levantado por el Instituto Geográfico y Estadístico.

El convento de Santo Domingo fue abandonado por los frailes durante la guerra de Independencia y ocupado como cuartel y como polvorín por las tropas invasoras, y la iglesia como almacén de paja (Esteban 2014: 103104). Tras la salida de los franceses, los frailes volvieron al convento, aunque poco les duró la estabilidad, ya que, durante el trienio liberal (1820-1823), tras la clausura y expolio del edificio, los frailes se vieron obligados a emigrar al convento de Santa María de Albarracín (Esteban 2014: 100). En 1822, se subastó parte de los bienes del convento, proceso que tuvo continuidad con

\footnotetext{
19 Tal y como describe en la descripción gráfica del proyecto (Furriel y Gironza $1852 \mathrm{a}$ [plano] y $1852 \mathrm{~b}$ [plano]).
}

la desamortización de Mendizábal en 1836, con el que terminó la vida conventual del edificio.

Desde el año 1847, entrando desde la plaza de San Juan, se ubicaron todas las oficinas de Hacienda con sus anexos, y en el segundo piso el cuartel de la Guardia Civil, que tuvo la entrada junto a la puerta de Valencia (Madoz 1849: XIV, 742). En 1870, junto a las oficinas de Hacienda o Tesorería, el edificio acogió el Gobierno Civil y el Instituto (Blasco 1870: 140), que se había instalado en el ex-convento en 1854 (Novella 1988: 121), tras su paso por la Casas de la Comunidad. El edificio desapareció a causa de los daños sufridos durante la guerra civil de 1936.

El convento de la Merced, extramuros, quedó muy arruinado en la guerra de Independencia (Blasco 1870: 139), tras haber sido utilizado como cuartel para la tropa. En 1830, un huracán creó grandes destrozos en su fábrica, y, en 1836, con la desamortización de Mendizábal, se subastaron todos sus bienes, dando por concluida su vida como convento (Esteban 2014: 77-79). En 1849, el edificio alojaba la escuela de niños más concurrida de Teruel, aunque el edificio estaba muy deteriorado y destruido en su tercera parte (Madoz 1849: XIV, 743). El edificio aún existía en 1881, y así lo atestigua el plano de la ciudad editado en esta fecha, pero ya desaparece definitivamente a comienzos del siglo $\mathrm{XX}^{20}$ (Fig. 11).

El convento de San Francisco, tras la desamortización de Mendizábal en 1836, quedó en manos de la autoridad local, que lo arrendaría a terceros. En 1849 queda constatado que su iglesia se empleaba como almacén de maderas, además de albergar el único trinquete o juego de pelota (Madoz 1849: XIV, 744). Posteriormente, si se atiende a la cartografía histórica, sería utilizado como cárcel, pues así aparece en los planos de la ciudad de 1869 y 1881 (Fig. 12).

Al finalizar el siglo XIX, el estado del edificio era de total deterioro, de tal forma que el arquitecto municipal, que en esos momentos era Pablo Monguió, determinó su estado de ruina, por lo que se procedió a su demolición: "El ayuntamiento ha dispuesto la completa demolición del exconvento de San Francisco, excepto la iglesia, por constituir una amenaza a la seguridad del tránsito público, según dictamen facultativo"21.

\footnotetext{
20 Aparece representado en el plano de Teruel publicado por el depósito de la guerra en 1881 (CEME 1881 [plano]), pero en el plano de Teruel editado por A. Martín Editor ca. 1914 (Martín ca. 1914 [plano]) o el plano de 1912 levantado por el Instituto Geográfico y Estadístico (DGIGE 1912 [plano]) no existe la edificación anexa a la iglesia.

${ }^{21}$ Eco de Teruel: Periódico democrático y de intereses generales. Año XIV. Núm. 664. Domingo 5 de febrero de 1889. p. 5.
} 

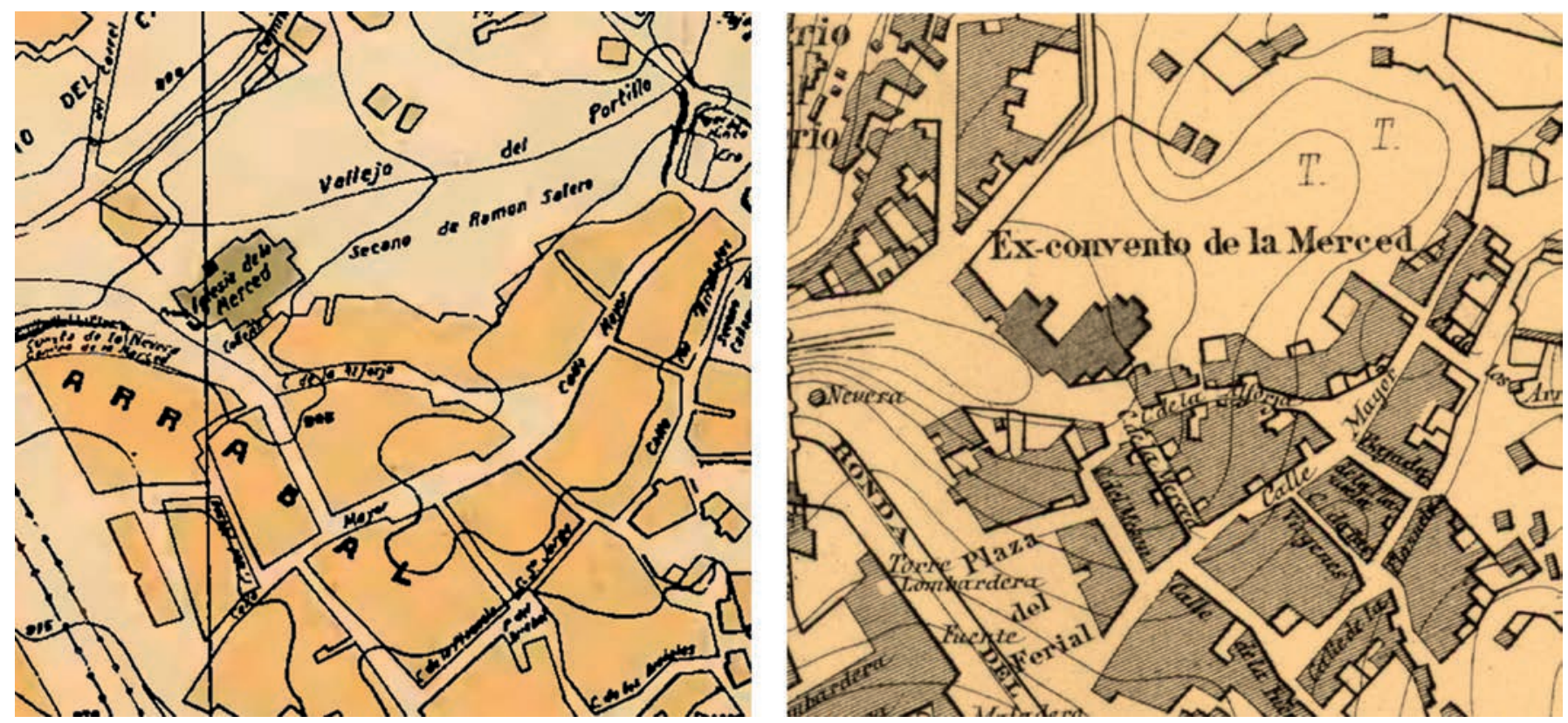

Fig. 11. Izq.: Detalle de plano de Teruel editado por A. Martín, ca. 1914 (MARTÍn ca. 1914 [plano]). Drch.: Detalle de plano Teruel editado en 1881. (CEME 1881 [plano]).
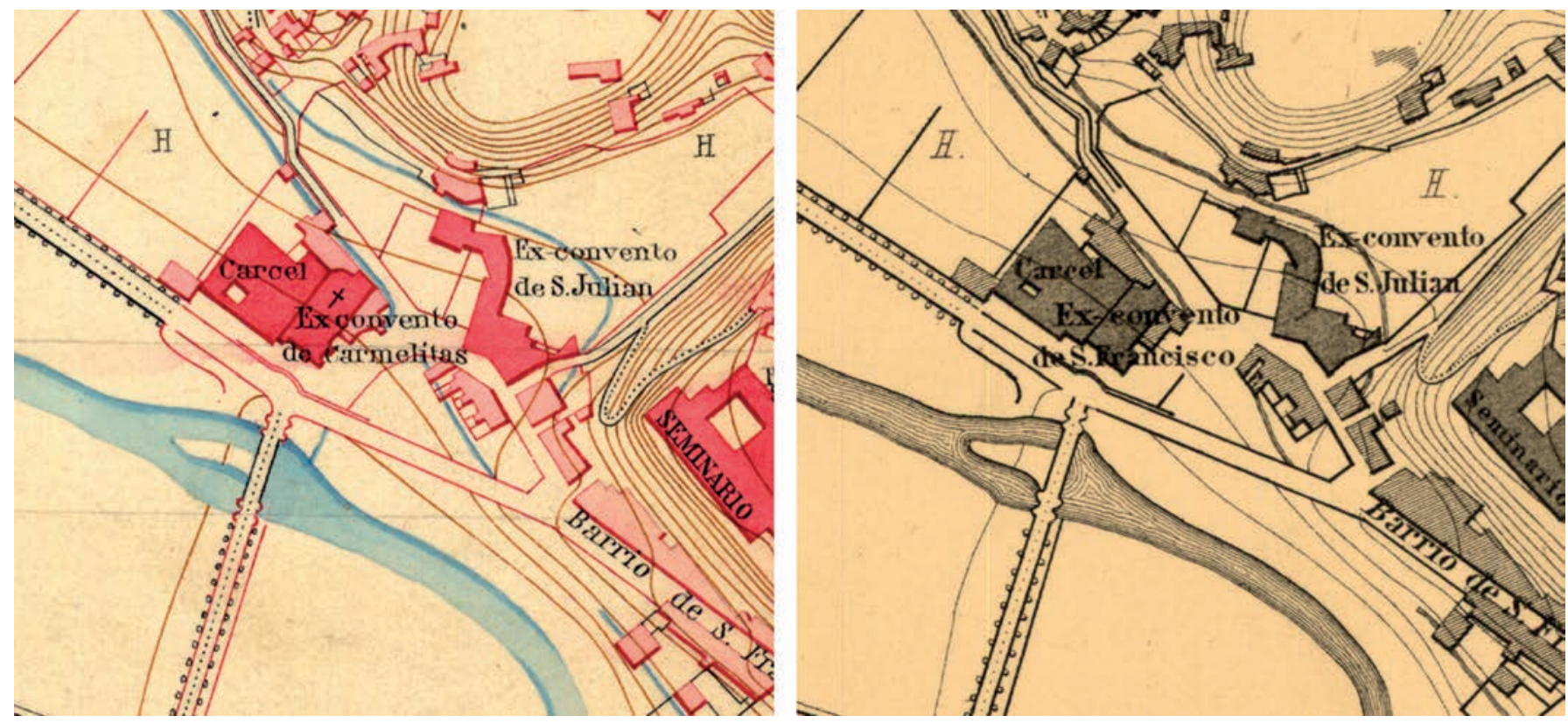

Fig. 12. Izq.: Detalle de plano Teruel editado en 1869 (CEME 1869 [plano]). Drch.: Detalle de plano Teruel editado en 1881 (CEME 1881 [plano]).

Se realizó un nuevo proyecto para el convento, que fue reedificado en 1901 e inaugurado en 1902, posiblemente obra del mismo Pablo Monguió (Pérez 1998: 33). El proyecto, que tiene reminiscencias góticas por el empleo del arco apuntado en los vanos de planta baja, incluyendo el acceso, cuenta con planta baja, a modo de zócalo, marcada mediante imposta resaltada, y dos plantas más, cuyas ventanas quedan unidas por franjas verticales de ladrillo que unifican conceptualmente ambos pisos. En cuanto a la materialidad, es predominante el uso de la piedra combinado con el del ladrillo en elementos singulares. Antonio Pérez lo clasifica como pre-modernista (Pérez 1998: 32) junto con otros edificios con semejanzas compositivas, materiales y cronológicas de la ciudad de Teruel. 


\section{CONCLUSIONES}

Los acontecimientos bélicos acaecidos durante el siglo XIX, unidos a las nuevas corrientes de pensamiento, supusieron para la ciudad de Teruel un fuerte impacto sobre su paisaje urbano. La adaptación del recinto para su defensa requirió de un complejo sistema de fortificación, del que hoy en día no quedan apenas restos, y que en su mayor parte no sobreviviría a su propia centuria. Además, las trasformación física y funcional, o incluso la desaparición, de los edificios conventuales, que en su mayor parte ocupaban la cornisa oeste de la muela, intensificó el proceso transformador, cambiando completamente la percepción de la ciudad desde el exterior.

El análisis de los documentos escritos entre los que destacan las fuentes hemerográficas o las numerosas descripciones realizadas por viajeros o estudiosos de la época, junto con las fuentes gráficas principalmente grabados, algunas de las primeras fotografías de la ciudad o cartografías históricas, y las fuentes directas que perviven, han permitido recomponer una imagen que, pese a su cercanía histórica, parece haber caído en el olvido. Un patrimonio que es imprescindible recuperar para poder interpretar las huellas que la historia ha dejado impresas en la ciudad.

\section{AGRADECIMIENTOS}

Para la elaboración de la presente investigación debemos agradecer a Antonio Pérez Sánchez quien nos ha facilitado fotos de su archivo personal, así como por compartir con nosotros su profundo conocimiento de la ciudad de Teruel. De igual modo, queremos agradecer a José Ángel Gil su disposición explicándonos y enseñándonos in situ el proyecto de restauración de la muralla lo que nos ha permitido tener contacto directo con los vestigios de la antigua fortificación de las guerras carlistas.

Por último, es necesario nombrar al Centro Geográfico del Ejército y al Archivo General Militar de Madrid por permitir la reproducción de los valiosos fondos de sus archivos.

\section{FUENTES CARTOGRÁFICAS}

Ayuntamiento de Teruel 2013: [Cartografia (planimetría y altimetría) de los núcleos urbanos del término municipal de Teruel]. [plano vectorial]. 1:500. Hojas de la 1 a 7: 104 archivos. Inédito. UTM ETRS89 Huso 30.

Campuzano, J. J. 1842: "Plano de Teruel y sus inmediaciones", en: Campuzano, J. J., Reconocimiento y Proyecto de comunicaciones militares desde Morella a Alcañiz, Teruel y Castellón [atlas]: hechos por Don José Campuzano y Don Manfredo Fanty. Varias escalas. Madrid: Depósito de la Guerra. lám.17. Disponible en: Cartoteca del Centro Geográfico del Ejército_SG Ar. 5-At. 204.

Cuerpo del Estado Mayor del Ejército (España) 1835: Croquis de Teruel y sus inmediaciones [plano]. [ca. 1:6.800]. Inédito. $560 \mathrm{~mm}$ x $660 \mathrm{~mm}$. Disponible en: España. Ministerio de Defensa. Instituto de Historia y Cultura Militar. Archivo General Militar de Madrid. (IHCM TE-3-4).

Cuerpo del Estado Mayor del Ejército (España) ca. 1838: Plano del Proyecto de fortificación de Teruel [plano]. [ca. 1:1.200]. Inédito. 302 mm x 466 mm. Disponible en: España. Ministerio de Defensa. Centro Geográfico del Ejército (CGE_Ar.F-T.5-C.5-188).

Cuerpo del Estado Mayor del Ejército (España) ca. 1840: Croquis de Teruel y sus inmediaciones [mapa]. [ca. 1:22.000]. Inédito. $306 \mathrm{~mm} \mathrm{x}$ $240 \mathrm{~mm}$. Disponible en: España. Ministerio de Defensa. Centro Geográfico del Ejército (CGE Ar.F-T.5-C.5-189).

Cuerpo del Estado Mayor del Ejército (España) 1869: Plano de Teruel [plano]: 1869. 1:5.000. Inédito. $585 \mathrm{~mm}$ x $590 \mathrm{~mm}$. Disponible en: España. Ministerio de Defensa. Centro Geográfico del Ejército (CGE Ar.F-T.5-C.5-195bis).

Cuerpo del Estado Mayor del Ejército (España) 1881: Plano de Teruel [plano]: levantado por una comisión de oficiales del Cuerpo de E.M. del Ejto y publicado por el Depósito de la Guerra en 1881. 1:5.000. [sl]: Deposito de la Guerra. $540 \mathrm{~mm}$ x $560 \mathrm{~mm}$. Disponible en: España. Ministerio de Defensa. Centro Geográfico del Ejército (CGE_Ar.FT.5-C.5-197(2)).

Dirección General del Instituto Geográfico y Estadístico (España) 1912: Plano de población de Teruel [plano]. 1:1000. Inédito. Compuesto por 11 hojas de $550 \mathrm{~mm}$ x $750 \mathrm{~mm}$. Disponible en: Instituto Geográfico Nacional (IGN-CNIG-Planos de Población, 1912-Hojas 440910- 440920).

Ejército Francés 1811: Plan du Séminaire de Teruel: avec les travaux defensive éxécutés en 1811 [plano]. Escala gráfica de 50 metros. Inédito. Disponible en: Archives du Génie, Service Historique de l'Armée de Terre (SHAT). Château de Vincennes, París.

Furriel y Gironza, M. 1852a: Plano de las plantas del ex-Convento de Carmelitas de Teruel y proyecto en el mismo de un Cuartel ... [plano]. Cuerpo de Yngenieros del Egercito. Dirección Subinspección de Aragón. Comandancia de Zaragoza. Teruel. 1:200 del pie de Burgos. Inédito. $680 \mathrm{~mm}$ x $1050 \mathrm{~mm}$. Disponible en: España. Ministerio de Defensa. Instituto de Historia y Cultura Militar. Archivo General Militar de Madrid. (IHCM_TE-3-5).

Furriel y Gironza, M. 1852b: Elevaciones y perfile del ex-Convento de Carmelitas de Teruel, del proyecto de un Cuartel ... [plano]: Cuerpo de Yngenieros del Egercito. Dirección Subinspección de Aragón. Comandancia de Zaragoza. Teruel. 1:200 del pie de Burgos. Inédito. $680 \mathrm{~mm}$ x $1050 \mathrm{~mm}$. Disponible en: España. Ministerio de Defensa. Instituto de Historia y Cultura Militar. Archivo General Militar de Madrid. (IHCM TE-3-6)

Martín, A. (ed.) ca. 1914: Plano de Teruel [plano]. 1:4.000. Barcelona: Alberto Martín, $520 \mathrm{~mm}$ x $360 \mathrm{~mm}$. Disponible en: Biblioteca Virtual del Patrimonio Bibliográfico ( ${ }^{o}$ control: BVPB20110198565). Original en España. Ministerio de Defensa. Instituto de Historia y Cultura Militar. Archivo General Militar de Madrid. (Colección: SH. Signatura: AT-16B/9).

Miguel y Polo, M. 1835: Alzado planta y perfiles del puente de la Reyna $N^{a}$. Sra. Ysabel 2a [plano]. 1:145. Inédito. $435 \mathrm{~mm}$ x $611 \mathrm{~mm}$. Disponible en: España. Ministerio de Defensa. Instituto de Historia y Cultura Militar. Archivo General Militar de Madrid. (IHCM_TE-1-21).

Ortiz De Pinedo, C. 1850: Plano de la planta baja del Seminario de Teruel [plano]. 1:200 del pie de Burgos. Inédito. $565 \mathrm{~mm}$ x $440 \mathrm{~mm}$. Disponible en: Cartoteca del Centro Geográfico del Ejército (CGE _Ar.F-T.5-C.5-191). 


\section{BIBLIOGRAFÍA}

Blasco, C. 1870: Historia de Teruel por Cosme Blasco y Val. Imprenta de J. Alpuente. Teruel.

Clairac y Saénz, P. 1884: Diccionario general de arquitectura e ingeniería. (Tomo III). Imprenta de A. Pérez Durrull. Madrid.

Esteban Mateo, L. 2014: Monasterios desaparecidos en Teruel capital (siglos XIII-XIX). Tirant Lo Blanch. Valencia.

Ibáñez Gómez, M. 1895: Topografía médica de Teruel por Don Miguel Ibáñez Gómez. Imp. de la Beneficencia. Teruel.

Ibáñez González, J. 2010: "La arqueología urbana del Teruel medieval y moderno: resultados y visión crítica”, en Ortega, J. M. y Escriche Jaime, C. (eds.), Actas de las I Jornadas de Arqueología Medieval en Aragón. Balances y novedades, pp. 289-332. Instituto de Estudios Turolenses / Museo de Teruel, Teruel.

Lafoz Rabaza, H. 2009: Actas de la Junta Superior de Aragón y Castilla (1809). (Fuentes históricas Aragonesas, 49). Instituto Fernando el Católico: Excma. Diputación Provincial. Zaragoza.

Lozano Bartolozzi, M. 2011: Historia del urbanismo en España. Vol. II, Siglos XVI, XVII y XVIII. Cátedra. Madrid.

Madoz, P. 1849: Diccionario geográfico-estadístico-histórico de España y sus posesiones de ultramar. Vol. XIV. Imprenta del Diccionario geográfico estadístico-histórico de Pascual Madoz. Madrid.

Miñano y Bedoya, S. 1826-1828: Diccionario geográfico-estadístico de España y Portugal. Tomo VIII. Imprenta de Pierart-Peralta. Madrid.

Novella Mateo, A. 1988: La transformación urbana de Teruel a través de los tiempos. Instituto de Estudios Turolenses. Teruel.

Pérez Sánchez, A. 1998: "El modernismo en Teruel”, en Pérez Sánchez, A. y Martínez Verón, J., El modernismo en la ciudad de Teruel, pp. 10-119. Instituto de Estudios Turolenses (CSIC), Excma. Diputación Provincial de Teruel, Teruel.
Pérez Sánchez, A. 2013: "Zoom a los fotógrafos de Teruel”, en Albero Miguel, R., Pérez Sánchez, A. y Sáenz Guallar, F. J. Teruel en el cambio de siglo: Fotografias de Jaime Fernández Fuertes (1852-1928), pp. 37-65. Instituto de Estudios Turolenses, Teruel.

Pérez Sánchez, A. 2014: "La evolución urbana de Teruel", en Martínez González, M. y Latorre Ciria, J. M. (coords.), Historia de la ciudad de Teruel, pp. 505-541. Instituto de Estudios Turolenses, Teruel.

Pruneda, P. 1866: "Crónica de la provincia de Teruel escrita por Pedro Pruneda”, en Crónica general de España. Ronchi y Compañía, Madrid.

Rújula López, P. 2014: “Despertar en el siglo XIX. Cambio económico, activismo político y capitalidad", en Martínez González, M. y Latorre Ciria, J. M. (coords.), Historia de la ciudad de Teruel, pp. 315-348. Instituto de Estudios Turolenses, Teruel.

Sancho Mir, Miguel. 2015: Transformaciones urbanas en la ciudad de Teruel: reconstrucción y análisis gráfico. Tesis doctoral. Universidad Politécnica de Valencia: Dpto. de Expresión Gráfica Arquitectónica.

Sebastián López, S. 1963: Los monumentos de la ciudad de Teruel. Instituto de Estudios Turolenses / Diputación Provincial de Teruel, Teruel.

Terán, F. 1999: Historia del urbanismo en España. Vol. III, siglos XIX y XX. Cátedra, Madrid.

Valverde y Álvarez, E. 1886: Guía del antiguo reino de Aragón: Provincias de Zaragoza, Huesca y Teruel. Imp. de Fernando Cao y Domingo de Val, Madrid.

Villanueva Herrero, J. R. 2010a: "El XIX, un siglo convulso (I): Guerra de la Independencia y contiendas carlistas”, en Losantos Salvador, A. (coord.), Comunidad de Teruel, pp. 127-132. Diputación General de Aragón, Departamento de Política Territorial, Justicia e Interior, Zaragoza.

Villanueva Herrero, J. R. 2010b: "El XIX, un siglo convulso (II): del republicanismo al regeneracionismo", en Losantos Salvador, A. (coord.), Comunidad de Teruel, pp. 135-141. Diputación General de Aragón, Departamento de Política Territorial, Justicia e Interior, Zaragoza. 